\title{
Climatology of the mesopause relative density using a global distribution of meteor radars
}

\author{
Wen Yi ${ }^{1,2}$, Xianghui Xue ${ }^{1,2,5}$, Iain M. Reid ${ }^{3,4}$, Damian J. Murphy ${ }^{6}$, Chris M. Hall ${ }^{7}$, Masaki Tsutsumi ${ }^{8}$, Baiqi Ning ${ }^{9}$, \\ Guozhu Li ${ }^{9}$, Robert A. Vincent ${ }^{3,4}$, Jinsong Chen ${ }^{10}$, Jianfei Wu ${ }^{1,2}$, Tingdi Chen ${ }^{1,2}$, and Xiankang Dou ${ }^{1}$ \\ ${ }^{1}$ CAS Key Laboratory of Geospace Environment, Department of Geophysics and Planetary Sciences, \\ University of Science and Technology of China, Hefei, China \\ ${ }^{2}$ Mengcheng National Geophysical Observatory, School of Earth and Space Sciences, \\ University of Science and Technology of China, Hefei, China \\ ${ }^{3}$ ATRAD Pty Ltd., Thebarton, South Australia, Australia \\ ${ }^{4}$ School of Physical Sciences, University of Adelaide, Adelaide, South Australia, Australia \\ ${ }^{5}$ Synergetic Innovation Center of Quantum Information and Quantum Physics, \\ University of Science and Technology of China, Hefei, China \\ ${ }^{6}$ Australian Antarctic Division, Kingston, Tasmania, Australia \\ ${ }^{7}$ Troms $\varnothing$ Geophysical Observatory, UiT - The Arctic University of Norway, Troms $\emptyset$, Norway \\ ${ }^{8}$ National Institute of Polar Research, Tachikawa, Japan \\ ${ }^{9}$ Key Laboratory of Earth and Planetary Physics, Institute of Geology and Geophysics, \\ Chinese Academy of Sciences, Beijing, China \\ ${ }^{10}$ National Key Laboratory of Electromagnetic Environment, China Research Institute of Radiowave Propagation, \\ Qingdao, China
}

Correspondence: Xianghui Xue (xuexh@ustc.edu.cn) and Iain M. Reid (ireid@atrad.com.au)

Received: 30 September 2018 - Discussion started: 15 November 2018

Revised: 19 May 2019 - Accepted: 23 May 2019 - Published: 6 June 2019

\begin{abstract}
The existing distribution of meteor radars located from high- to low-latitude regions provides a favorable temporal and spatial coverage for investigating the climatology of the global mesopause density. In this study, we report the climatology of the mesopause relative density estimated using multiyear observations from nine meteor radars, namely, the Davis Station $\left(68.6^{\circ} \mathrm{S}, 77.9^{\circ} \mathrm{E}\right)$, Svalbard $\left(78.3^{\circ} \mathrm{N}\right.$, $\left.16^{\circ} \mathrm{E}\right)$ and Troms $\varnothing\left(69.6^{\circ} \mathrm{N}, 19.2^{\circ} \mathrm{E}\right)$ meteor radars located at high latitudes; the Mohe $\left(53.5^{\circ} \mathrm{N}, 122.3^{\circ} \mathrm{E}\right)$, Beijing $\left(40.3^{\circ} \mathrm{N}, 116.2^{\circ} \mathrm{E}\right)$, Mengcheng $\left(33.4^{\circ} \mathrm{N}, 116.6^{\circ} \mathrm{E}\right)$ and Wuhan $\left(30.5^{\circ} \mathrm{N}, 114.6^{\circ} \mathrm{E}\right)$ meteor radars located in the midlatitudes; and the Kunming $\left(25.6^{\circ} \mathrm{N}, 103.8^{\circ} \mathrm{E}\right)$ and Darwin $\left(12.3^{\circ} \mathrm{S}, 130.8^{\circ} \mathrm{E}\right)$ meteor radars located at low latitudes. The daily mean relative density was estimated using ambipolar diffusion coefficients derived from the meteor radars and temperatures from the Microwave Limb Sounder (MLS) on board the Aura satellite. The seasonal variations in the Davis Station meteor radar relative densities in the southern po-
\end{abstract}

lar mesopause are mainly dominated by an annual oscillation (AO). The mesopause relative densities observed by the Svalbard and Troms $\varnothing$ meteor radars at high latitudes and the Mohe and Beijing meteor radars at high midlatitudes in the Northern Hemisphere show mainly an AO and a relatively weak semiannual oscillation (SAO). The mesopause relative densities observed by the Mengcheng and Wuhan meteor radars at lower midlatitudes and the Kunming and Darwin meteor radars at low latitudes show mainly an AO. The SAO is evident in the Northern Hemisphere, especially at high latitudes, and its largest amplitude, which is detected at the Troms $\varnothing$ meteor radar, is comparable to the AO amplitudes. These observations indicate that the mesopause relative densities over the southern and northern high latitudes exhibit a clear seasonal asymmetry. The maxima of the yearly variations in the mesopause relative densities display a clear latitudinal variation across the spring equinox as the latitude decreases; these latitudinal variation characteristics may be re- 
lated to latitudinal changes influenced by gravity wave forcing. In addition to an $\mathrm{AO}$, the mesopause relative densities over low latitudes also clearly show an intraseasonal variation with a periodicity of 30-60 d.

\section{Introduction}

The temperatures, winds and densities in the mesopause region are essential for studying the dynamics and climate, including both short-term wave motions (e.g., gravity waves, tides and planetary waves) and long-term climate variations (e.g., interannual variations, seasonal variations and intraseasonal variations), of the middle and upper atmosphere. The climatology of the temperature and wind within the mesopause region has been studied for decades using ground-based instruments such as meteor radars, mediumfrequency (MF) radars, lidars (Dowdy et al., 2001; Dou et al., 2009; Li et al., 2008, 2012, 2018) and satellite instruments (Garcia et al., 1997; Remsberg et al., 2002; Xu et al., 2007). It is well established that the semiannual oscillation (SAO) dominates the seasonal variations in both the wind and the temperature in the low-latitude mesosphere (Li et al., 2012), whereas the annual oscillation (AO) dominates the seasonal variations in the mid- and high-latitude mesosphere (Remsberg et al., 2002; Xu et al., 2007; Dou et al., 2009). However, in contrast to temperature and wind observations, longterm continuous measurements of the atmospheric density in the mesopause region are still quite rare; as a result, the seasonal variations in the mesopause, especially with regard to its global structure, are still unclear.

Meteor radar operates both day and night under all kinds of weather and geographical conditions and provides good long-term observations; consequently, meteor radar is a powerful technique for studying the dynamics and climate of the mesopause region, including its wind fields and temperatures (e.g., Hocking et al., 2004; Holdsworth et al., 2006; Hall et al., 2006, 2012; Stober et al., 2008, 2012; Yi et al., 2016; Lee et al., 2016; Holmen et al., 2016; Liu et al., 2017; Lima et al., 2018; Ma et al., 2018). In addition to acquiring wind and temperature measurements, meteor radar has also been applied in recent years to estimate the atmospheric density in the mesopause region. For instance, the variation in the peak height of meteor radar detections can be used to estimate changes in the mesopause density (e.g., Clemesha and Batista, 2006; Stober et al., 2012, 2014; Lima et al., 2015; Liu et al., 2016). However, the seasonal variations in the peak height are not affected by the atmospheric density alone; they are also significantly influenced by the properties of meteoroids, especially the meteor velocity (Stober et al., 2012; Yi et al., 2018b). Furthermore, the mesospheric densities can also be estimated from meteor-radar-derived ambipolar diffusion coefficients, and the mesospheric temperatures can be derived from other measurements (e.g., Takahashi et al.,
2002; Yi et al., 2018b). Therefore, in this study, we apply ambipolar diffusion coefficients derived from a global distribution of meteor radars in addition to temperature measurements simultaneously obtained by the Microwave Limb Sounder (MLS) on board the Aura satellite to determine the mesopause relative density. In addition, long-term observations of global atmospheric densities are used to study the latitudinal and seasonal variations in the mesopause region. Descriptions of the instrument datasets, the method, and the error estimation approach are presented in Sect. 2 . Then, the seasonal variations in the mesopause density are presented in Sect. 3, followed by a composite analysis in Sect. 4. Finally, a summary is provided in Sect. 5 .

\section{Data and methods}

In this study, data from nine meteor radars, namely, the Davis Station $\left(68.6^{\circ} \mathrm{S}, 77.9^{\circ} \mathrm{E}\right)$, Svalbard $\left(78.3^{\circ} \mathrm{N}, 16^{\circ} \mathrm{E}\right)$, Troms $\varnothing\left(69.6^{\circ} \mathrm{N}, 19.2^{\circ} \mathrm{E}\right)$, Mohe $\left(53.5^{\circ} \mathrm{N}, 122.3^{\circ} \mathrm{E}\right)$, Beijing $\left(40.3^{\circ} \mathrm{N}, 116.2^{\circ} \mathrm{E}\right)$, Mengcheng $\left(33.4^{\circ} \mathrm{N}, 116.5^{\circ} \mathrm{E}\right)$, Wuhan $\left(30.6^{\circ} \mathrm{N}, 114.4^{\circ} \mathrm{E}\right)$, Kunming $\left(25.6^{\circ} \mathrm{N}, 108.3^{\circ} \mathrm{E}\right)$ and Darwin $\left(12.3^{\circ} \mathrm{S}, 130.5^{\circ} \mathrm{E}\right)$ meteor radars (hereinafter referred to as DMR, SMR, TMR, MMR, BMR, McMR, WMR, KMR and DwMR, respectively), were used. Table 1 summarizes the operational frequencies, geographic locations and observational time periods for the meteor radars used in this study. These meteor radars all belong to the ATRAD meteor detection radar (MDR) series and are similar to the Buckland Park meteor radar system described by Holdsworth et al. (2004). Figure 1 shows the locations of these nine meteor radars. The SMR and TMR are located in the northern high latitudes, whereas the MMR, BMR, McMR and WMR are positioned in the northern midlatitudes, and the KMR is situated in the northern low latitudes. In contrast, we have only two meteor radars, namely, the DMR located in the southern high latitudes and the DwMR situated in the southern low latitudes, in the Southern Hemisphere because it is covered primarily by oceans.

The ambipolar diffusion coefficient $\left(D_{\mathrm{a}}\right)$ observed by a meteor radar describes the rate at which plasma diffuses in a neutral background and is a function of both the atmospheric temperature, $T$, and the atmospheric density, $\rho$, as given by

$\rho=2.23 \times 10^{-4} K_{0} \frac{T}{D_{\mathrm{a}}}$,

where $K_{0}$ is the ionic zero-field mobility, which is assumed to be $2.5 \times 10^{-4} \mathrm{~m}^{-2} \mathrm{~s}^{-1} \mathrm{~V}^{-1}$ (Hocking et al., 1997). Using the relation given by Eq. (1), measurements of the temperature and $D_{\mathrm{a}}$ from meteor radars can be used to retrieve the neutral mesospheric density (see, e.g., Takahashi et al., 2002; Yi et al., 2018b).

The MLS instrument on board the Earth Observing System (EOS) Aura spacecraft was launched in 2004. For this investigation, the Aura MLS temperature (Schwartz et al., 
Table 1. Main operation parameters, geographic coordinates and observational time periods for the meteor radars used in this study.

\begin{tabular}{lllll}
\hline & Meteor radar & Geographic coordinates & Frequency & Data used in this study \\
\hline \multirow{5}{*}{ Northern Hemisphere } & Svalbard (SMR) & $78.3^{\circ} \mathrm{N}, 16^{\circ} \mathrm{E}$ & $31 \mathrm{MHz}$ & Jan 2005-Dec 2016 \\
& Troms $\emptyset$ (TMR) & $69.6^{\circ} \mathrm{N}, 19.2^{\circ} \mathrm{E}$ & $30.3 \mathrm{MHz}$ & Jan 2005-Dec 2016 \\
& Mohe (MMR) & $53.5^{\circ} \mathrm{N}, 122.3^{\circ} \mathrm{E}$ & $38.9 \mathrm{MHz}$ & Aug 2011-Apr 2018 \\
& Beijing (BMR) & $40.3^{\circ} \mathrm{N}, 116.2^{\circ} \mathrm{E}$ & $38.9 \mathrm{MHz}$ & Jan 2011-Apr 2018 \\
& Mengcheng (McMR) & $33.4^{\circ} \mathrm{N}, 116.5^{\circ} \mathrm{E}$ & $38.9 \mathrm{MHz}$ & Sep 2014-Apr 2018 \\
& Wuhan (WMR) & $30.6^{\circ} \mathrm{N}, 114.4^{\circ} \mathrm{E}$ & $38.9 \mathrm{MHz}$ & Oct 2012-Aug 2017 \\
& Kunming (KMR) & $25.6^{\circ} \mathrm{N}, 108.3^{\circ} \mathrm{E}$ & $37.5 \mathrm{MHz}$ & Apr 2011-Dec 2014 \\
\hline \multirow{2}{*}{ Southern Hemisphere } & Davis (DMR) & $68.6^{\circ} \mathrm{S}, 77.9^{\circ} \mathrm{E}$ & $33.2 \mathrm{MHz}$ & Jan 2005-Dec 2016 \\
& Darwin (DwMR) & $12.3^{\circ} \mathrm{S}, 130.5^{\circ} \mathrm{E}$ & $33.2 \mathrm{MHz}$ & Jan 2006-Dec 2009
\end{tabular}

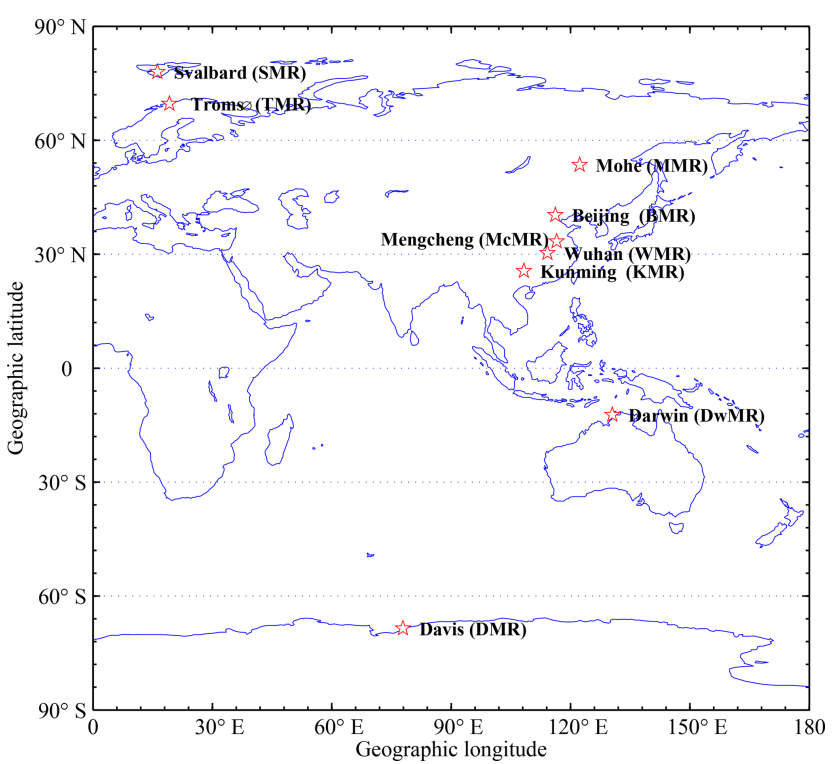

Figure 1. The locations of the meteor radars used in this study.

2008) and geopotential height data (version 4) were restricted to data obtained within a $10^{\circ} \times 20^{\circ}$ bounding box centered on each of the abovementioned meteor radar locations. Geometric heights, $z$, for Aura MLS observations were computed from geopotential heights, $z_{\mathrm{g}}$, via the equation $z=z_{\mathrm{g}} R_{\mathrm{E}}(\phi)\left[R_{\mathrm{E}}(\phi)-z_{\mathrm{g}}\right]^{-1}$ (Younger et al., 2014), where $R_{\mathrm{E}}(\phi)$ is the radius of Earth at latitude $\phi$, based on the WGS84 ellipsoid (Decker, 1986). The daily averaged MLS temperature and geometric height observations were interpolated into $1 \mathrm{~km}$ bins between 85 and $95 \mathrm{~km}$ to produce temperature profiles.

In this study, in order to avoid the possibility of excessive error in the height estimates of individual meteors, trail detections for this study were restricted to zenith angles of less than $60^{\circ}$. All meteor radars in this study transmit a $3.6 \mathrm{~km}$ long, 4 bit complimentary coded pulse with a pulse repetition frequency (PRF) of $430 \mathrm{~Hz}$, so the meteor radar range sampling resolution is $1.8 \mathrm{~km}$ (Holdsworth et al., 2008). With the criterion of zenith $<60^{\circ}$, the meteor height estimate uncertainty (range sampling resolution $\times \cos$ (zenith)) should be less than $\pm 1 \mathrm{~km}$. The daily neutral mesospheric densities from 85 to $95 \mathrm{~km}$ were estimated using the daily mean $D_{\text {a }}$ from the nine meteor radars and the Aura MLS temperatures using Eq. (1); more details are described by Yi et al. (2018b). Yi et al. (2018b) showed that the $\log _{10} D_{\text {a }}$ profiles derived from meteor radars are approximately linear with respect to the altitude in the range from 85 to $95 \mathrm{~km}$, which indicates that mainly ambipolar diffusion governs the evolution of meteor trails in this region. In general, the $\log _{10} D_{\text {a }}$ profiles measured by meteor radars have larger slopes than those derived from Sounding of the Atmosphere using Broadband Emission Radiometry (SABER) (Yi et al., 2018b) and MLS (Younger et al., 2015) measurements. To avoid the influence of the bias in $D_{\mathrm{a}}$, in the present study, we use the relative variation in the density to examine the climatology of the global mesopause density.

There is an uncertainty in $D_{\text {a }}$ caused by the estimation of the decay time of meteor echoes (e.g., Cervera and Reid, 2000; Holdsworth et al., 2004); unfortunately, this uncertainty is quite difficult to estimate from the radar system directly. In addition, the number of precise, simultaneously observed temperature and density measurements in the study region is insufficient to estimate the absolute error in $D_{\text {a }}$ through a comparison. Yi et al. (2018b) compared simultaneous observations of $D_{\mathrm{a}}$ acquired by two co-located meteor radars at Kunming and found that the relative errors in the daily mean $D_{\mathrm{a}}$ and the density at $90 \mathrm{~km}$ obtained from the KMR should be less than $5 \%$ and $6 \%$, respectively. Here, to estimate the relative errors in $D_{\mathrm{a}}$ and the density, we conduct a similar approach using simultaneous meteor echoes observed by two co-located meteor radars with different frequencies (33 and $55 \mathrm{MHz}$ ) at Davis Station. The 33 and $55 \mathrm{MHz}$ meteor radars at Davis Station are described in related studies (see, e.g., Reid et al., 2006; Younger et al., 2014).

Figure $2 \mathrm{a}$ shows the height distributions of meteor detections in $1 \mathrm{~km}$ bins on 1 January and 1 July 2006 for the 33 and $55 \mathrm{MHz}$ meteor radars at Davis Station. The meteor count ob- 

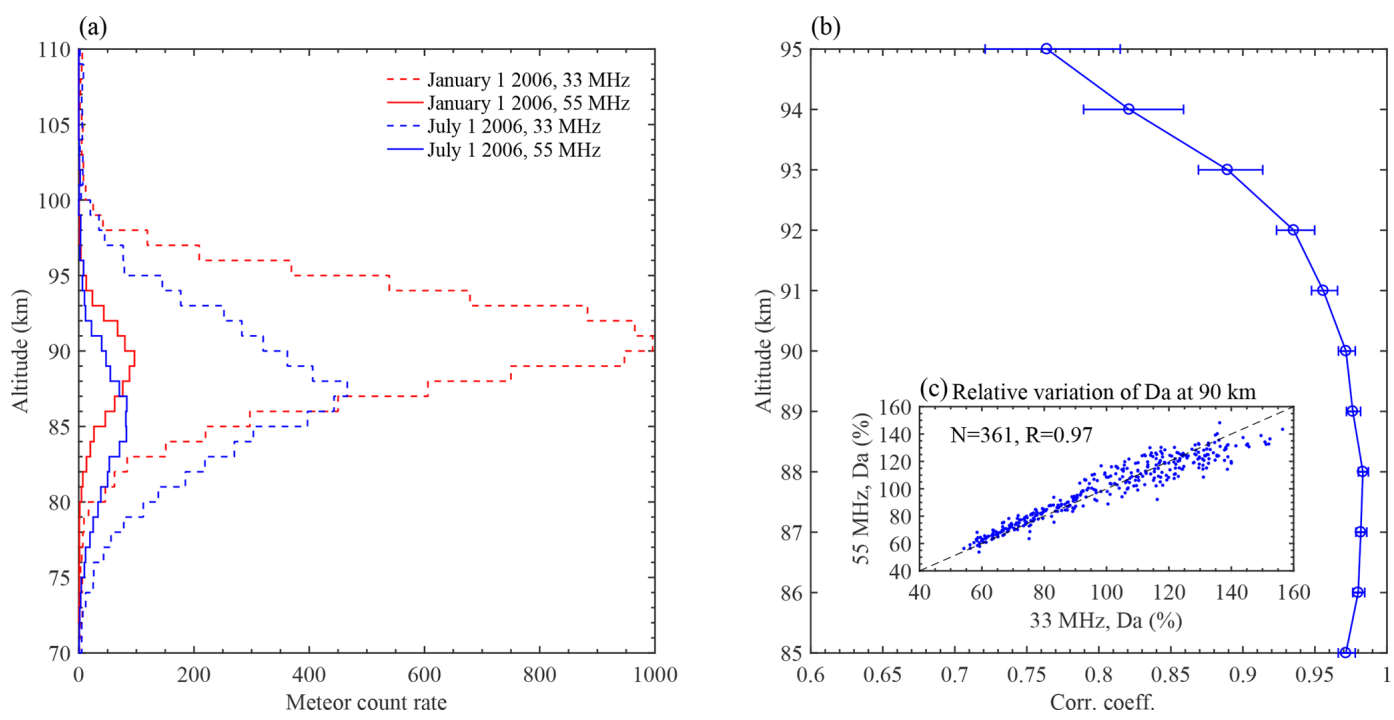

Figure 2. (a) The height distributions of meteor detections in $1 \mathrm{~km}$ bins on 1 January and 1 July 2006 from the 33 and $55 \mathrm{MHz}$ meteor radars at Davis Station. (b) Height variation in the correlation coefficient between the $D_{\mathrm{a}}$ observed simultaneously by the 33 and $55 \mathrm{MHz}$ meteor radars at Davis Station in 2006. The error bars indicate the lower and upper bounds of the $95 \%$ confidence interval for each coefficient. (c) Comparison of the variations in the daily mean $D_{\mathrm{a}}$ (blue dots) at $90 \mathrm{~km}$ simultaneously observed from the 33 and $55 \mathrm{MHz}$ meteor radars at Davis Station in 2006. The percentage variations in $D_{\mathrm{a}}$ with respect to the yearly mean $D_{\mathrm{a}}$ in 2006 . $N$ represents the number of days observed by these two radars in 2006 , and $R$ denotes the linear correlation coefficient.

served by the $55 \mathrm{MHz}$ meteor radar is much lower than that observed by the $33 \mathrm{MHz}$ meteor radar because the former is a mesosphere-stratosphere-troposphere (MST) radar operating with time-interleaved stratosphere-troposphere (ST), meteor and polar mesosphere summer echoes (PMSE) modes (see, e.g., Reid et al., 2006). Figure 2b shows the correlation coefficients between the $D_{\text {a }}$ observed simultaneously by the two co-located meteor radars from 85 to $95 \mathrm{~km}$. The correlation coefficients are higher than 0.96 below $92 \mathrm{~km}$, and they become lower as the altitude increases above $92 \mathrm{~km}$; this occurs mainly because the meteor count (as shown in Fig. 2a) obtained by the $55 \mathrm{MHz}$ meteor radar above $92 \mathrm{~km}$ is too low to provide a good precision in $D_{\mathrm{a}}$. The strong correlation between the $D_{\mathrm{a}}$ measurements from the two independent meteor radars indicates that the variations in $D_{\mathrm{a}}$ are dominated by the same geophysical variations (i.e., gravity waves, tides and planetary waves) from below as well as by disturbances by geomagnetic forcing from above (Yi et al., 2017, 2018a) rather than by random systemic errors; therefore, the difference between the two $D_{\text {a }}$ measurements is considered to be representative of the relative uncertainty in $D_{\mathrm{a}}$.

The MLS temperature has an accuracy of $1-3 \mathrm{~K}$ from 316 to $0.001 \mathrm{hPa}$ (Schwartz et al., 2008). The vertical resolution of MLS measurements near the mesopause region (about $90 \mathrm{~km})$ is $\sim 3-4 \mathrm{~km}$. This may introduce a bias between the interpolated temperatures and the actual mesopause temperatures because of the reversal temperature gradient in the mesopause region. In order to estimate the uncertainties caused by the temperature interpolation, we also compared the relative the interpolated MLS temperatures between the SABER temperatures over the Mohe meteor radar. The relative uncertainty in the density induced by the interpolated MLS temperature uncertainty would be less than $3 \%$ based on the present values. Comprehensive consideration in Table 2 shows a summary of the relative uncertainties in the density from 85 to $95 \mathrm{~km}$. The relative density uncertainties are less than $6 \%$ below $92 \mathrm{~km}$ and become larger as the altitude increases above $92 \mathrm{~km}$. However, under real-world conditions, the meteor counts from the nine meteor radars used in this study are much larger than those from the $55 \mathrm{MHz}$ meteor radar, and, hence, it is reasonable to believe that the uncertainties in the relative density above $92 \mathrm{~km}$ would be lower than this estimate of $6 \%$. The density scale height near $90 \mathrm{~km}$ over the Mohe meteor radar is approximately $6 \mathrm{~km}$, which means an increase of $1 \mathrm{~km}$ in geometric height would correspond to a density decrease of approximately $17 \%$, which may indicate that the relatively uncertainty of the density estimation is much smaller than $1 \mathrm{~km}$.

\section{Seasonal variations in the global mesopause relative density}

Figure 3 shows the monthly mean mesopause relative densities in the southern polar region derived from the DMR and in the northern polar region derived from the SMR and TMR between 2005 and 2016. As shown in Fig. 3a, the DMR relative densities are dominated by an $\mathrm{AO}$ with a maximum during the spring and a minimum during the early winter. The 
Table 2. The relative uncertainties in $D_{\mathrm{a}}$ and the density from 85 to $95 \mathrm{~km}$.

\begin{tabular}{lrrrrrrrrrrr}
\hline Altitude (km) & 85 & 86 & 87 & 88 & 89 & 90 & 91 & 92 & 93 & 94 & 95 \\
\hline Relative uncertainties in $D_{\mathrm{a}}(\%)$ & 3 & 2 & 2 & 2 & 2 & 3 & 4 & 6 & 11 & 18 & 24 \\
Relative uncertainties in the density (\%) & 4.2 & 3.6 & 3.6 & 3.6 & 3.6 & 4.2 & 5.2 & 6.7 & 11.4 & 18.2 & 24.2 \\
\hline
\end{tabular}

annual variations in the DMR relative densities are approximately $65 \%$ of the mean density. Younger et al. (2015) developed a novel technique using meteor radar echo decay times from the DMR to determine the height of a constant-density surface in the mesopause region and found that the height of the constant-density surface is also dominated by an AO. In the northern polar region, the SMR relative densities mainly show an AO and a relatively weak SAO with a clear maximum during the spring. However, the minima of the SMR relative densities are not as regular as the DMR relative densities, and they appear approximately during the summer and winter. The TMR relative densities mainly show an AO and $\mathrm{SAO}$ with a clear maximum during the spring and two distinct minima during the summer and winter. As the SMR and TMR are in the northern polar region, the SMR and TMR relative densities show a similar annual variation; however, the semiannual variations in the TMR relative densities are more obvious than those of the SMR relative densities.

To further examine the periodicities present in the mesopause relative densities derived from the meteor radars, Lomb-Scargle periodograms were calculated for the entire observational period of the densities in each $1 \mathrm{~km}$ bin from 85 to $95 \mathrm{~km}$. Figure 4 shows the contours of the Lomb-Scargle periodograms of the mesopause relative densities obtained from the DMR, SMR and TMR. The periodograms of the DMR relative densities in Fig. 4a are clearly dominated by an $\mathrm{AO}$ as well as a relatively weak $\mathrm{SAO}$; the largest amplitude of the AO appears at $87 \mathrm{~km}$, where it is $20 \%$ of the mean DMR densities. The periodograms of the SMR relative densities mainly show an $\mathrm{AO}$ and $\mathrm{SAO}$, and the amplitudes of the $\mathrm{AO}$ and SAO at $90 \mathrm{~km}$ are approximately $12 \%$ and $8 \%$, respectively, of the mean SMR densities. The TMR mainly shows an $\mathrm{AO}$ and SAO, and the amplitudes of the $\mathrm{AO}$ and SAO at $90 \mathrm{~km}$ are approximately $11 \%$ and $10 \%$, respectively. In addition to an $\mathrm{AO}$ and $\mathrm{SAO}$, the northern polar mesospheric densities from the SMR and TMR also exhibit clear seasonal periodicities with quasi- $120 \mathrm{~d}$ and quasi- $90 \mathrm{~d}$ oscillations.

Figure 5 shows the monthly mean mesospheric relative densities at northern midlatitudes derived from the MMR, BMR, McMR and WMR. The MMR monthly mean relative densities (Fig. 5a) from August 2012 to April 2018 at higher midlatitudes clearly show both an $\mathrm{AO}$ and an SAO; the AO clearly reaches a maximum in the spring (April), whereas the SAO shows two distinct minima: one clearly appears in the summer above $90 \mathrm{~km}$, and another clearly appears in the winter below $90 \mathrm{~km}$. As shown in Fig. 5b, the BMR monthly mean relative densities from January 2011 to April 2018 show mainly an $\mathrm{AO}$ with a maximum during the spring and a minimum during the summer. The McMR monthly mean relative densities (Fig. 5c) from October 2014 to April 2018 show seasonal variations similar to those exhibited by the BMR relative densities with a clear minimum during the summer and a maximum during the spring. As shown in Fig. 5d, the WMR monthly mean relative densities from October 2012 to September 2017 show mainly an $\mathrm{AO}$ with a maximum during the late winter and a minimum during the summer. As the WMR is located close to the low latitudes, the annual variations in the WMR relative densities are much smaller than those in the densities observed by meteor radars at high latitudes and higher midlatitudes.

Figure 6 displays the contours of the Lomb-Scargle periodograms of the mesopause relative densities from the MMR, BMR, McMR and WMR. The MMR relative densities (Fig. 6a) show mainly an AO and SAO; the amplitudes of the $\mathrm{AO}$ reach a maximum at $87 \mathrm{~km}$, where the amplitude is approximately $8 \%$ of the MMR mean densities, while the amplitudes of the SAO are larger than those of the AO above $90 \mathrm{~km}$ with a maximum that is approximately $7 \%$ of the MMR mean densities at $93 \mathrm{~km}$. The BMR and McMR relative densities (Fig. 6b and c, respectively) show similar periodograms; they exhibit mainly an $\mathrm{AO}$ and a relatively weak SAO. In contrast, the WMR relative densities are dominated by an $\mathrm{AO}$ above $89 \mathrm{~km}$; however, below $89 \mathrm{~km}$, they show both an SAO and an AO.

Figure 7a shows the KMR monthly mean relative densities in the northern low latitudes from April 2011 to December 2014. The KMR relative densities show mainly an AO with a maximum during the winter and a minimum during the summer. Figure $7 \mathrm{~b}$ shows the DwMR relative densities at southern low latitudes from January 2006 to June 2009. The DwMR relative densities exhibit a large data gap; however, the data still provide the opportunity to investigate the climatology of the mesospheric density at southern low latitudes. The seasonal variations in the DwMR relative densities are more complicated than those in the KMR relative densities and clearly show intraseasonal (with a periodicity of 30-60 d) oscillations. To more clearly examine the seasonal variations in the mesospheric densities, Fig. 8 shows the Lomb-Scargle periodograms of the KMR and DwMR relative densities. The largest component of the KMR relative densities is an $\mathrm{AO}$ above $87 \mathrm{~km}$, followed by an SAO, a $90 \mathrm{~d}$ oscillation and a $60 \mathrm{~d}$ oscillation; below $87 \mathrm{~km}$, the $\mathrm{SAO}$ becomes more obvious in the KMR relative densities, which can also be seen in Fig. 7a. The DwMR relative densities 

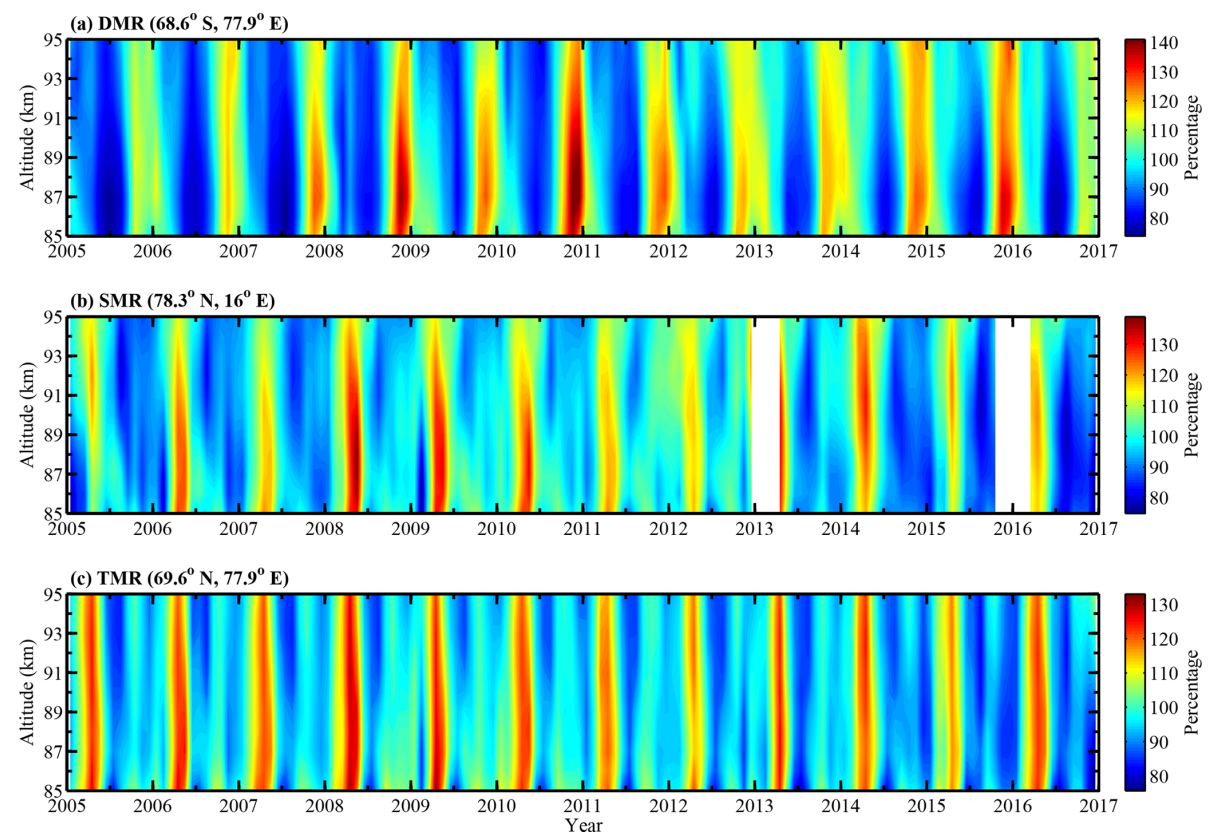

Figure 3. Variations in the monthly mean relative densities at altitudes from 85 to $95 \mathrm{~km}$ obtained from the DMR, SMR and TMR between 2005 and 2016. The color bars indicate the percentage variation in the monthly mean density relative to the mean density from the total observational time period.
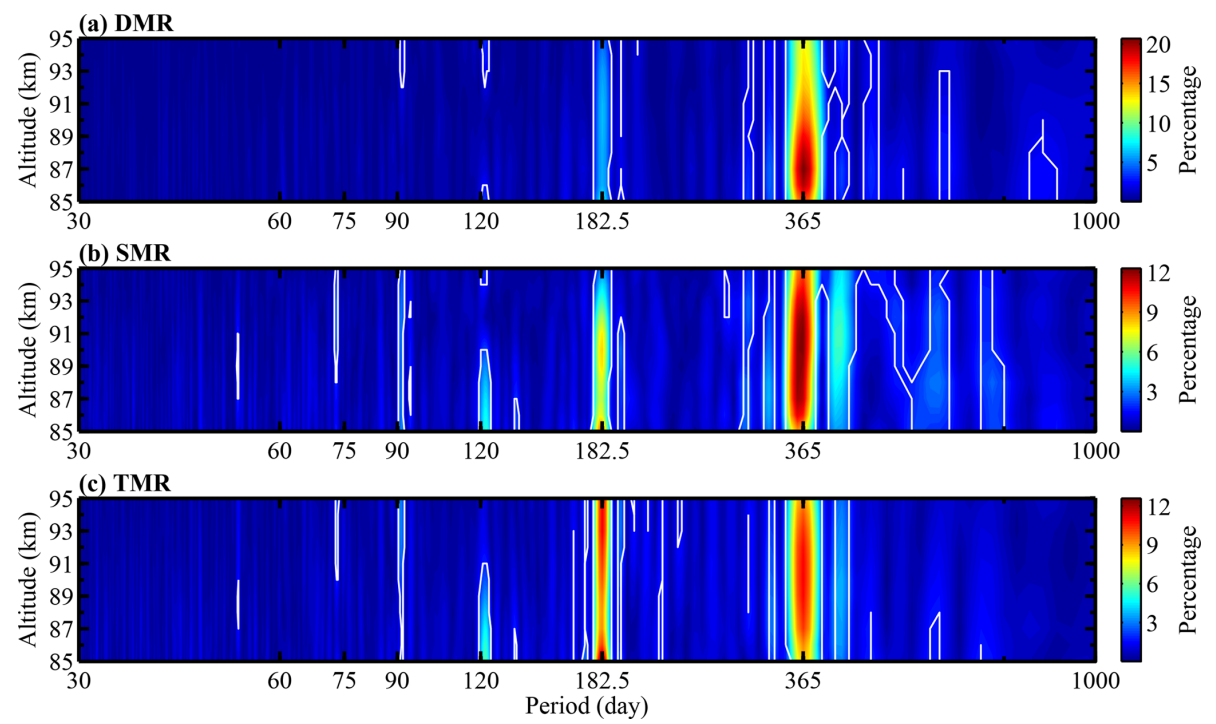

Figure 4. Contours of the Lomb-Scargle spectral (see, e.g., Lomb, 1976; Scargle, 1982) relative amplitudes of the (a) DMR, (b) SMR and (c) TMR densities. The white lines represent the $99 \%$ significance level.

show both an $\mathrm{AO}$ and an $\mathrm{SAO}$ above $92 \mathrm{~km}$. In addition to seasonal variations, the DwMR relative densities also exhibit broad oscillations with periodicities ranging from 30 to $60 \mathrm{~d}$; these periodic variations may be similar to intraseasonal oscillations (Eckermann and Vincent, 1994).

\section{Composite analysis for the global mesopause relative density}

In the results described above, we presented the year-to-year variability in the climatology of the global mesopause relative density. To better appreciate the latitudinal changes of the seasonal variations in the global mesopause relative density, we show a composite analysis for the nine meteor radar 

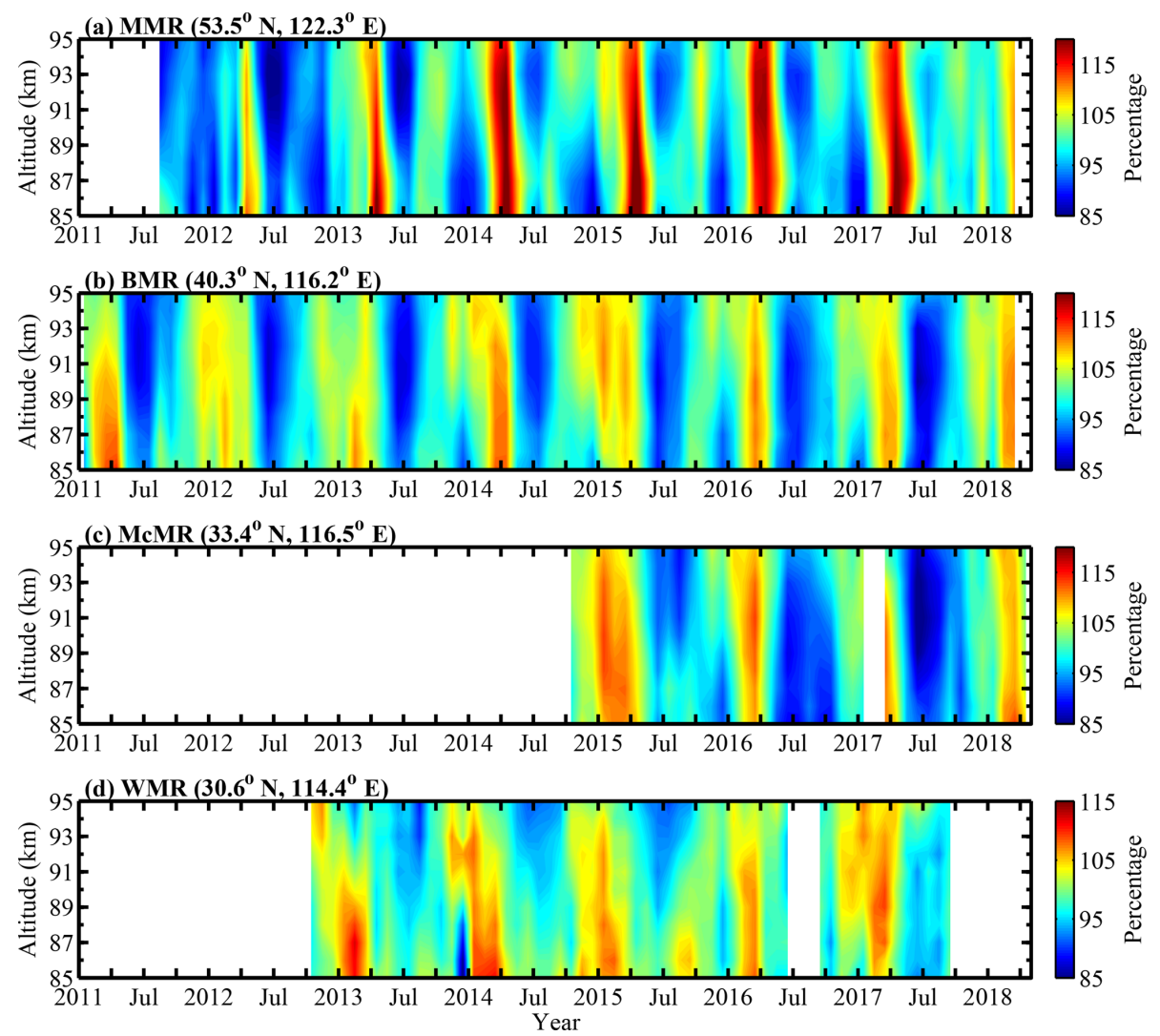

Figure 5. Same as Fig. 3 but for the MMR, BMR, McMR and WMR monthly mean relative densities.
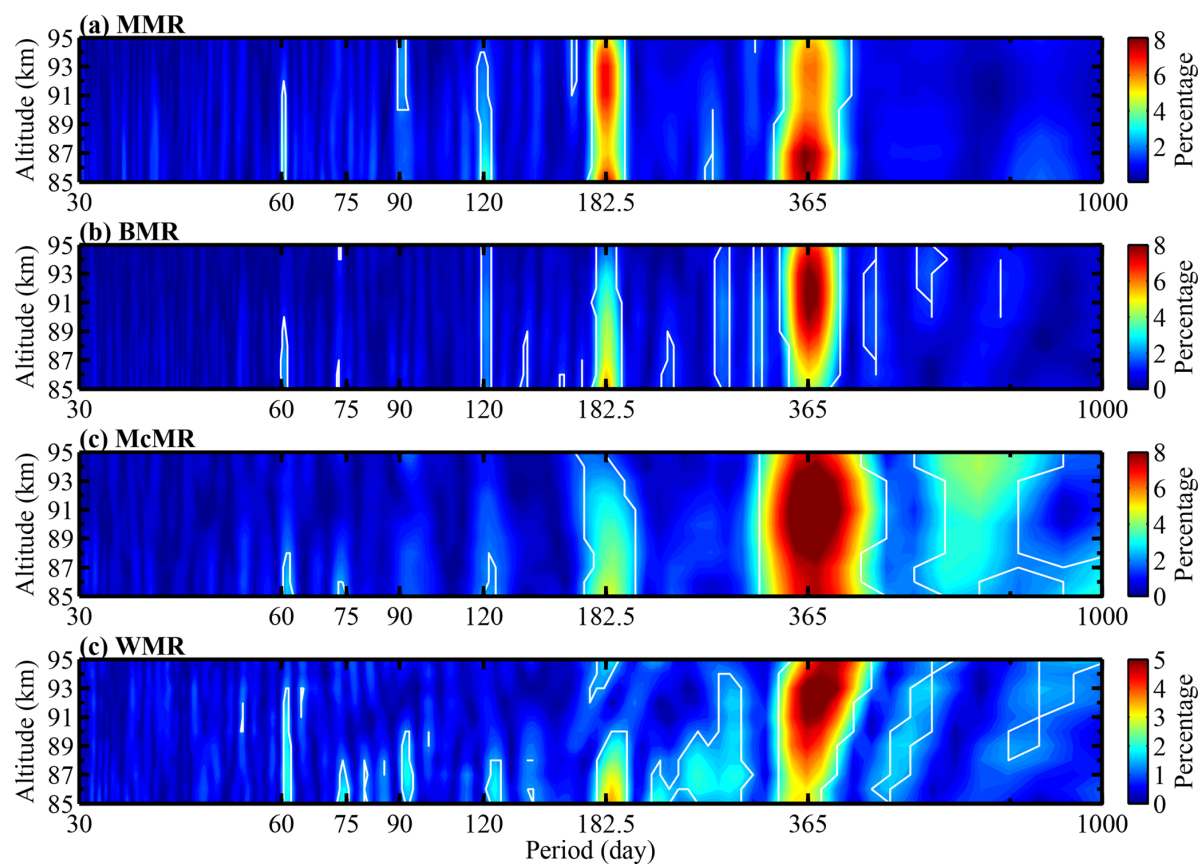

Figure 6. Same as Fig. 4 but for the MMR, BMR, McMR and WMR daily mean relative densities in the midlatitudes. 

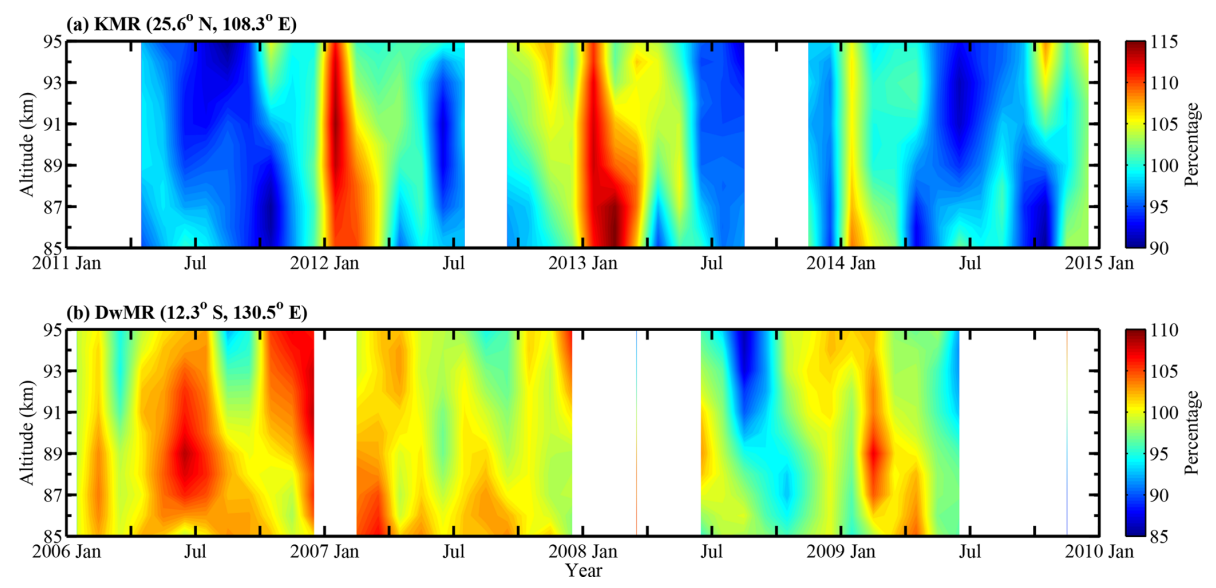

Figure 7. Same as Fig. 3 but for the KMR and DwMR monthly mean relative densities at low latitudes.

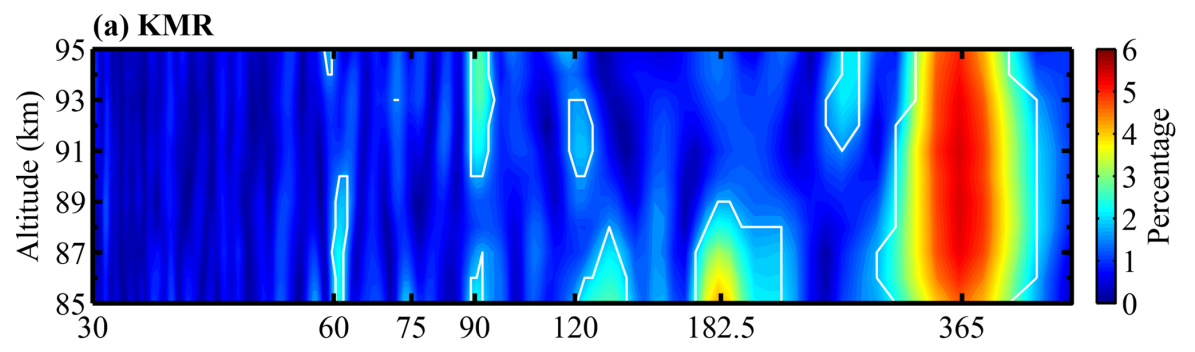

(b) DWMR

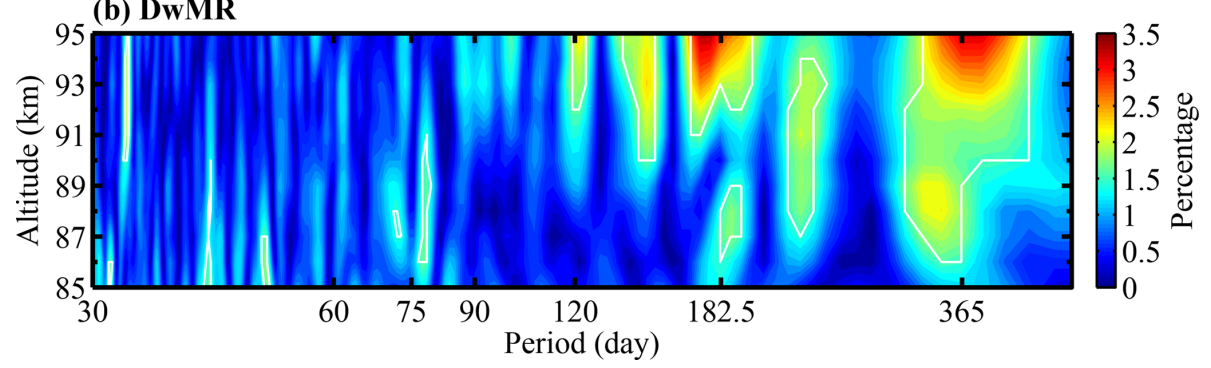

Figure 8. Same as Fig. 4 but for the KMR and DwMR daily mean relative densities at low latitudes.

measurements in Fig. 9. For this composite analysis, we first combine the nine meteor radar relative densities into a single year and then use a $30 \mathrm{~d}$ running average to obtain the seasonal variations in the global mesopause relative density. As shown in Fig. 9, several distinct features are present in the climatology of the global mesopause relative density.

It is clear that the seasonal variations in the mesopause relative densities exhibit latitudinal differences. The seasonal variations in the mesopause relative densities obtained from the SMR and TMR at northern high latitudes and the MMR at higher northern midlatitudes are similar; they display a primary maximum after the spring equinox and a minimum during the summer. In the northern midlatitudes, the mesopause relative densities from the BMR, McMR and WMR exhibit similar seasonal variations with a strong maximum near the spring equinox, a weak maximum before the winter solstice and a minimum during the summer. As shown in Fig. 9, the most noticeable feature is that the temporal evolution of the maximum mesopause relative density shifts as the latitude changes. For instance, the phase of the maximum shifts from spring (May) to winter (January) across the spring equinox from the high latitudes to the low latitudes in the Northern Hemisphere. Referring to the recent studies by Jia et al. (2018) and Ma et al. (2018), a similar feature was also present in the zonal mean winds simultaneously observed by the MMR, BMR, McMR and WMR at northern midlatitudes; they reported that the zonal winds above $85 \mathrm{~km}$ generally exhibit an annual variation with a maximum during the summer (eastward), and they further demonstrated that the wind shifts (i.e., the zero zonal wind) near the spring equinox. In addition, based on their results, we also find that the phase of the maximum in the zonal wind also shifts as the latitude decreases; meanwhile, the time at which the zonal wind shifts also demonstrates a transition across the spring equinox from 


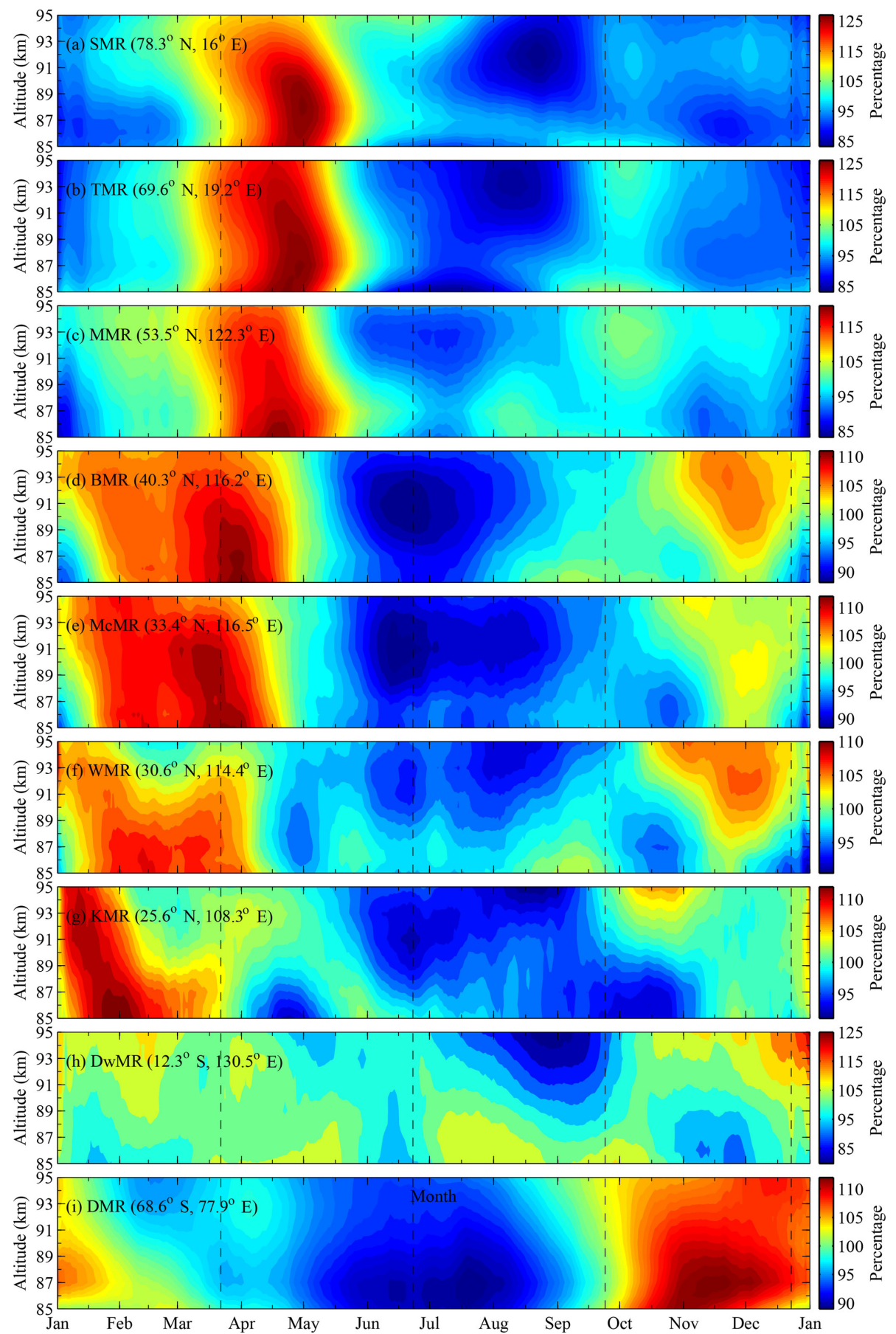

Figure 9. Contours of the composite $30 \mathrm{~d}$ running mean values of the mesopause densities in the composite year from the North Pole to the South Pole observed by the (a) SMR, (b) TMR, (c) MMR, (d) BMR, (e) McMR, (f) WMR, (g) KMR, (h) DwMR and (i) DMR. The dashed lines indicate the spring and autumn equinoxes and the summer and winter solstices. The color bars indicate the percentage variation in the $30 \mathrm{~d}$ running mean density relative to the mean density from the total observational time period.

the MMR to the WMR, which is similar to the observed mesopause relative densities shown in Fig. 9.

It is also worth noting that the minima of the global mesopause relative densities appear during June, July and August. The minima of the northern polar mesopause rela- tive densities obtained from the SMR and TMR occur during the Northern Hemisphere summer, while the DMR relative densities also show minima during the Southern Hemisphere winter. The mesopause relative densities over the northern midlatitudes obtained from the MMR, BMR, McMR and 
WMR all appear during the Northern Hemisphere summer. Because no measurements of the mesopause relative density over the southern midlatitudes are presented in this study, we cannot provide a comparison for the interhemispheric midlatitudes. With regard to the low latitudes, the mesopause relative densities obtained from the KMR clearly show a minimum during the Northern Hemisphere summer above $87 \mathrm{~km}$. In contrast, the DwMR relative densities in the southern low latitudes show a clear minimum during August and September, which is not during the expected Southern Hemisphere summer. These results reveal a seasonal asymmetry in the mesopause relative density in both hemispheres. During the Northern Hemisphere summer (the perihelion is on 4 July), the distance between the Sun and the Earth is 3.3\% longer than that during the Northern Hemisphere winter (the aphelion is on 3 January); therefore, the longer distance between the Sun and the Earth during the Northern Hemisphere summer leads to a reduction of $6.7 \%$ in the total solar radiation absorbed by the Earth, causing the Earth's atmosphere to shrink. This may explain why the global mesopause relative densities show a minimum during the Northern Hemisphere summer.

Figure 10 shows the harmonic fitting results for the composite global mesopause relative density (shown in Fig. 9). As shown in Fig. 10a, it is clear that the AO displays large amplitudes exceeding $10 \%$ at high latitudes (DMR, SMR and TMR); the maxima of the AO amplitudes observed by the DMR, SMR and TMR reach $21 \%, 13 \%$ and $12 \%$, respectively. Moreover, the amplitudes of the AO at southern high latitudes (DMR) are much larger than those at northern high latitudes (SMR and TMR). In the midlatitudes (MMR, BMR, McMR and WMR), the AO amplitudes observed by the McMR are stronger than those observed by the other three stations, especially the MMR and BMR situated in the higher midlatitudes. At low latitudes, the AO observed by the KMR is stronger than that observed by the DwMR at lower latitudes in the Southern Hemisphere as well as that observed by the WMR at higher latitudes.

Similarly, Fig. 10b shows the SAO amplitudes observed by the nine meteor radars; the SAO is much weaker than the AO, as shown in Fig. 10a. It is clear that the SAO is strongest at the TMR and that the amplitudes are comparable to those of the AO with a mean of approximately $10 \%$. The SAOs in the northern high latitudes (SMR and TMR) are stronger than those in the southern high latitudes (DMR). In the midlatitudes (MMR, BMR, McMR and WMR), the amplitudes of the SAOs decrease as the latitude decreases and roughly increase with decreasing altitude. The SAOs are much weaker in the low latitudes (KMR and DwMR), which is different from the temperature and horizontal wind in the low-latitude mesopause. The SAO is clearly the dominant seasonal variation in both the horizontal wind (Li et al., 2012) and the temperature (Xu et al., 2007) in the mesosphere at low latitudes. This might be because the seasonal variations in the mesopause density are influenced by the atmospheric dynam- ics as well as atmospheric equilibrium; however, this relationship is too complicated to understand at the moment.

Figure 10c and d show the phases of the AO and SAO, respectively, observed by the nine meteor radars. The phases of the AO show an approximately decreasing trend as the latitude decreases and a downward progression as the altitude increases. In addition, the phases of the SAO clearly show a decreasing trend from the high latitudes (SMR) to the low latitudes (KMR); this can also explain the shift in the temporal evolution of the mesopause density maxima as the latitude changes. The times at which the density maxima occur (Fig. 9) are consistent with the phases of the SAO shown in Fig. 10d. In addition, the phases of the SAO observed by the WMR, KMR and DwMR show a phase shift as the altitude increases; this is also reflected in Fig. 9. Placke et al. (2011) and Jia et al. (2018) calculated the gravity wave momentum fluxes in the mesosphere and lower thermosphere using the meteor radars at Collm, Germany $\left(51.3^{\circ} \mathrm{N}, 13.0^{\circ} \mathrm{E}\right)$, as well as Mohe and Beijing; they reported that the gravity wave variations exhibit an SAO at an altitude of approximately $90 \mathrm{~km}$ with a maximum during the summer and a secondary, weaker maximum during the winter as well as two minima around the equinoxes. Furthermore, Dowdy et al. (2001) suggested that radiative effects are stronger in the Southern Hemisphere and that gravity wave driving effects are more important in the Northern Hemisphere. These results may explain why the SAOs are more obvious at the SMR and TMR at high latitudes and at the MMR and BMR at higher midlatitudes as well as why the SAO at northern high latitudes is stronger than that at southern high latitudes.

Figure 11 shows a comparison of the climatology of the mesopause relative density at $90 \mathrm{~km}$ in the composite year among the meteor radars in addition to the mesopause relative densities calculated simultaneously by the US Naval Research Laboratory Mass Spectrometer and Incoherent Scatter (NRLMSISE-00) model (Picone et al., 2002) and Whole Atmosphere Community Climate Model version 4 (WACCM4). The WACCM is an atmospheric component of the Community Earth System Model (CESM) version 1.0.4 developed by the National Center for Atmospheric Research; the key features are described in detail in Marsh et al. (2013). In addition, the WACCM is a superset of the Community Atmospheric Model version 4 with 66 vertical hybrid levels from the surface to the lower thermosphere $(\sim 145 \mathrm{~km})$; the vertical spacing increases with the altitude from $\sim 1.1 \mathrm{~km}$ in the troposphere to $1.1-1.8 \mathrm{~km}$ in the lower stratosphere and $3.5 \mathrm{~km}$ above $\sim 65 \mathrm{~km}$. The horizontal resolution for the WACCM4 used here is $1.9^{\circ}$ latitude by $2.5^{\circ}$ longitude.

The comparisons shown in Fig. 11 reveal evident differences between the observations and models. The MSIS relative densities show a dominant $\mathrm{AO}$, the amplitude of which decreases as the latitude decreases. In the southern high latitudes, the MSIS relative densities generally exhibit an annual variation similar to those displayed by the DMR observations with a maximum during November and December 

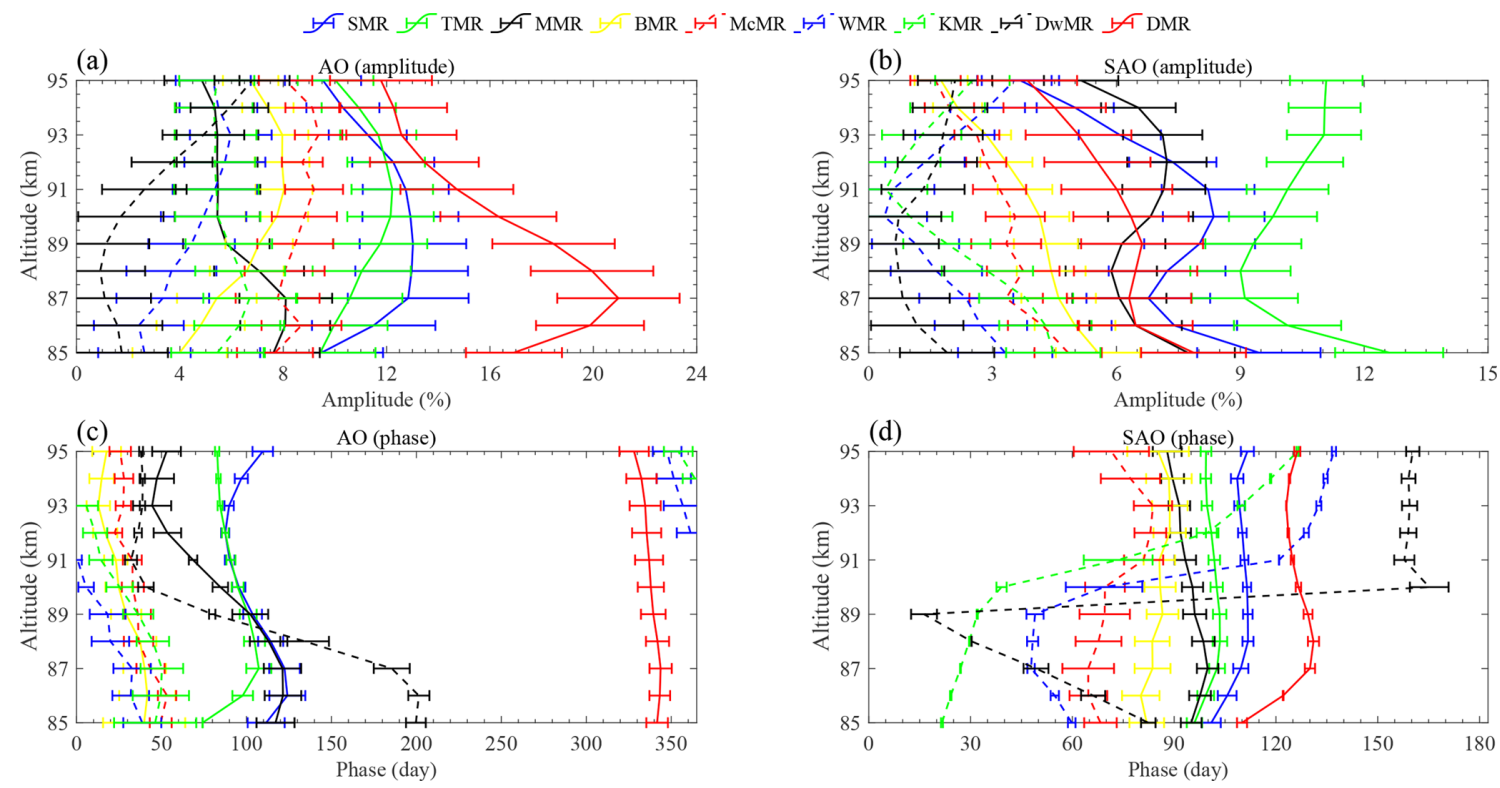

Figure 10. Amplitudes $(\mathbf{a}, \mathbf{b})$ and phases $(\mathbf{c}, \mathbf{d})$ of the $\mathrm{AO}$ and $\mathrm{SAO}$ observed by the nine meteor radars. The amplitude values indicate the percentage of the density relative to the mean density from the total observational time period.

and a minimum during July, but the AO shows a larger variation than do the DMR observations. In the Northern Hemisphere from the SMR to the McMR, the difference between the meteor radar observations and the MSIS model is obvious because the SAOs in the meteor radar observations are strong at these latitudes, while the SAO amplitude is much weaker in the MSIS model. At lower latitudes, the MSIS captures only the annual variations in the WMR, KMR and DwMR observations but fails to reproduce the other seasonal and intraseasonal variations. The WACCM relative densities show mainly annual and semiannual variations but almost fail to capture the seasonal variations in the mesopause density. However, it is worth noting that the WACCM relative densities show a minimum during June, July and August; this feature is similar to the meteor radar observations. The comparison between the observations and models demonstrates obvious inconsistencies, which indicate some limitations of the current models, such as the MSIS model and WACCM, regarding the seasonal behavior of the mesopause relative density.

The MSIS model is an empirical atmospheric model based on observations acquired over a decade ago; in particular, mesospheric density data were quite scarce at that time, which is the likely reason that the MSIS model exhibits obvious differences from the meteor radar observations. Moreover, the WACCM cannot directly provide atmospheric density estimates. Hence, in this study, we calculate the WACCM density at $90 \mathrm{~km}$ using the WACCM-simulated temperature and the geographic height corresponding to the pressure level. Previous studies indicated that WACCM-simulated temperatures are generally higher than lidar observations, but the WACCM temperatures can reproduce the major features of the climatology of the mesopause temperatures (see, e.g., $\mathrm{Li}$ et al., 2018). The accuracy of the pressure level (i.e., geographic height) is quite difficult to estimate because of the lack of corresponding observations. This study constitutes the first time we have compared the mesopause density simulated by the WACCM with meteor radar observations; hence, the remarkable differences in the seasonal variations between them are difficult to understand at the moment and are beyond the scope of this study.

\section{Summary}

Mesopause relative densities determined with data from a global distribution of meteor radars are used to investigate the climatology of the global mesopause relative density. The multiyear observations of the mesopause relative density involved nine meteor radars, namely, the Davis Station $\left(68.6^{\circ} \mathrm{S}, 77.9^{\circ} \mathrm{E}\right)$, Svalbard $\left(78.3^{\circ} \mathrm{N}, 16^{\circ} \mathrm{E}\right)$ and Troms $\varnothing\left(69.6^{\circ} \mathrm{N}, 19.2^{\circ} \mathrm{E}\right)$ meteor radars located at high latitudes; the Mohe $\left(53.5^{\circ} \mathrm{N}, 122.3^{\circ} \mathrm{E}\right)$, Beijing $\left(40.3^{\circ} \mathrm{N}\right.$, $\left.116.2^{\circ} \mathrm{E}\right)$, Mengcheng $\left(33.4^{\circ} \mathrm{N}, 116.6^{\circ} \mathrm{E}\right)$ and Wuhan $\left(30.5^{\circ} \mathrm{N}, 114.6^{\circ} \mathrm{E}\right)$ meteor radars located in the midlatitudes; and the Kunming $\left(25.6^{\circ} \mathrm{N}, 103.8^{\circ} \mathrm{E}\right)$ and Darwin $\left(12.4^{\circ} \mathrm{S}, 130.8^{\circ} \mathrm{E}\right)$ meteor radars located at low latitudes. The mesopause relative densities estimated from these nine meteor radars exhibit different seasonal and latitudinal variations. The main points of the latitudinal and seasonal variations in the mesopause relative density are summarized as follows: 

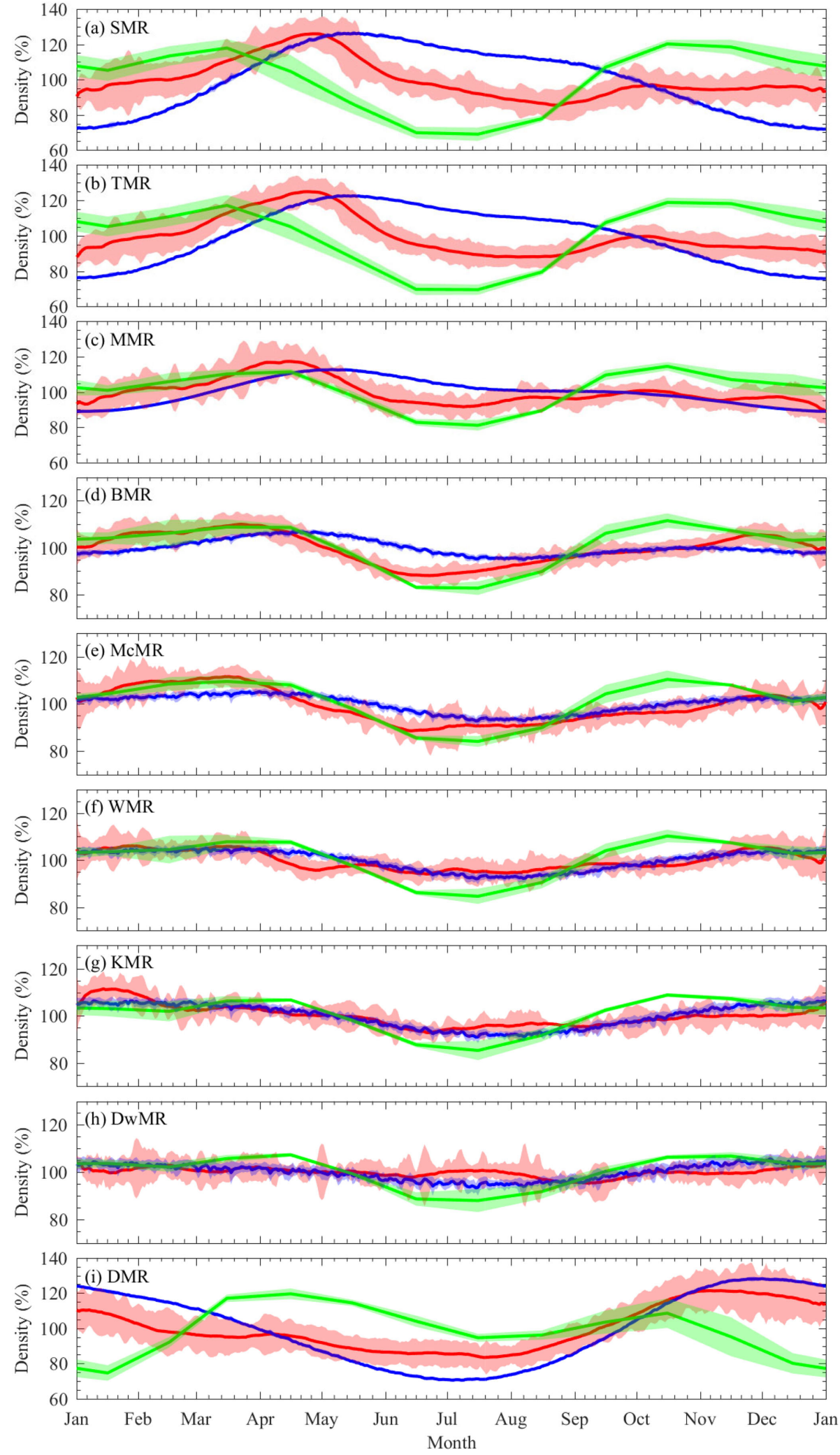

Figure 11. Comparisons of the mesopause relative densities at $90 \mathrm{~km}$ in the composite year among the meteor radars (solid red lines), the Mass Spectrometer and Incoherent Scatter (MSIS) model (solid blue lines) and the Whole Atmosphere Community Climate Model (WACCM) (solid green lines). The shaded areas represent the $30 \mathrm{~d}$ running averages and standard deviations of the composite density. 
1. In the southern high latitudes, the AO observed by the DMR dominates the seasonal variations with a maximum during the late spring and a minimum during the early winter. In the Northern Hemisphere from high to low latitudes (from the SMR to the KMR), the AOs dominate the seasonal variations in the mesopause relative densities, and the amplitudes decrease equatorward. In addition to AOs, SAOs are also evident in the Northern Hemisphere, especially at high latitudes, and their largest amplitude, which is detected at the TMR, is comparable to the $\mathrm{AO}$ amplitudes. Near the Equator, the mesopause relative densities observed by the DwMR show an AO and relatively weak intraseasonal oscillations with a periodicity of 30-60 d.

2. Interhemispheric observations indicate that the mesopause relative densities over the southern and northern polar regions show a clear seasonal asymmetry. The maxima of the yearly variations in the mesopause relative density exhibit a clear temporal variation across the spring equinox as the latitude decreases; these latitudinal variation characteristics may be related to the latitudinal variation in the global circulation of the mesosphere influenced by gravity wave forcing. In addition, the minima of the global mesopause relative densities basically appear during June, July and August. A possible explanation for this phenomenon is that the longer distance between the Sun and the Earth during the Northern Hemisphere summer leads to a reduction in the total solar radiation absorbed by the Earth that then causes the Earth's atmosphere to shrink. However, the actual mechanism cannot be comprehensively proven at the moment and thus remains an open question. Future observations and modeling are needed to more completely characterize and explain these phenomena.

3. Comparisons of the climatology of the mesopause relative density at $90 \mathrm{~km}$ among the observations from meteor radars are provided in addition to the mesopause relative densities calculated simultaneously by the MSIS model and WACCM. The MSIS model roughly captures the prevailing annual variation in the mesopause relative density at southern high latitudes and northern low latitudes. The WACCM relative densities show both annual and semiannual variations but almost fail to capture the seasonal variations in the mesopause density. The comparison results show the above inconsistencies between the observations and models, thereby indicating some limitations of the current models, such as the MSIS model and WACCM, regarding the seasonal behavior of the mesopause density.

In this study, we have reported global observations of the climatology of the mesopause relative density for the first time.
Knowledge of the atmospheric density is essential for understanding the relevant physical processes in the mesopause region as well as for providing a usual reference for lidars (e.g., Dou et al., 2009) or an input parameter for the airglow phenomenon (Reid et al., 2017; Takahashi et al., 2002). However, accurately predicting the changes in the neutral atmospheric density over time is crucial for determining the atmospheric drag on low-Earth-orbit satellites and directly governs the orbit cycles of satellites; moreover, safe launches and precise spacecraft landings also require accurate knowledge of the neutral atmospheric density. Despite the differences between the observations and model simulations, the mesopause densities derived from meteor radar observations still have great potential and practical applications because the global distribution of meteor radar instruments and their associated long-term and continuous datasets provide a wide range of aerospace applications and the potential to improve widely used empirical models.

Data availability. The Aura/MLS data are available from http://disc.sci.gsfc.nasa.gov/Aura/data-holdings/MLS (last access: 3 June 2019). The Davis meteor radar data are available from the Australian Antarctic Data Centre at https://data.aad.gov.au (last access: 3 June 2019). The Svalbard and Troms $\varnothing$ meteor radar data are available upon request from Chris Hall at the Troms $\varnothing$ Geophysical Observatory (chris.hall@uit.no). The Mohe, Beijing and Wuhan meteor radar data are available from http://data.meridianproject.ac.cn/ (last access: 3 June 2019). The Mengcheng and Kunming meteor radar data are available upon request from Wen Yi (yiwen@ustc.edu.cn).

Author contributions. WY designed the study, performed data analysis, prepared the figures and wrote the manuscript. XX initiated the study and contributed to the supervision and interpretation. IMR contributed to the supervision and interpretation, and helped write and edit the original manuscript. DJM provided the Davis meteor radar data. CMH and MT provided the Svalbard and Troms $\varnothing$ meteor radar data. BN and GL provided the Mohe, Beijing and Wuhan meteor radar data. RAV provided the Darwin meteor radar data. JC provided the Kunming meteor radar data. JW is responsible for the WACCM model. TC and XD contributed to the interpretation. All authors contributed to the discussion and interpretation.

Competing interests. The authors declare that they have no conflict of interest.

Special issue statement. This article is part of the special issue "Layered phenomena in the mesopause region (ACP/AMT interjournal SI)". It is a result of the LPMR workshop 2017 (LPMR2017), Kühlungsborn, Germany, 18-22 September 2017. 
Acknowledgements. We acknowledge support provided by the University of Adelaide and ATRAD Pty Ltd, as well as the provision of Davis meteor radar data by the Australian Antarctic Division; the provision of Nippon/Norway Svalbard and Troms $\emptyset$ meteor radar data by the National Institute of Polar Research and UiT The Arctic University of Norway; the provision of Mohe, Beijing and Wuhan meteor radar data by the Chinese Meridian Project and STERN (the Solar-Terrestrial Environment Research Network); the provision of Kunming meteor radar data by the China Research Institute of Radiowave Propagation (CRIRP); and the provision of Darwin meteor radar data by the University of Adelaide. Operation of the Davis meteor radar was supported under AAS projects 2529, 2668 and 4025.

Financial support. This research has been supported by the National Natural Science Foundation of China (grant nos. 41774158, 41474129 and 41674150) and the Youth Innovation Promotion Association of the Chinese Academy of Sciences (grant no. 2011324)), as well as the Chinese Meridian Project and the China Scholarship Council.

Review statement. This paper was edited by Robert Hibbins and reviewed by two anonymous referees.

\section{References}

Cervera, M. and Reid, I.: Comparison of atmospheric parameters derived from meteor observations with CIRA, Radio Sci., 35, 833-843, 2000.

Clemesha, B. and Batista, X.: The quantification of long-term atmospheric change via meteor ablation height measurements, J. Atmos. Sol.-Terr. Phy., 68, 1934-1939, 2006.

Decker, B.: World Geodetic System 1984, Def. Mapp. Agency Aerosp. Cent., St. Louis AFS, Mo, 1986.

Dou, X., Li, T., Xu, J., Liu, H., Xue, X., Wang, S., Leblanc, T., McDermid, S., Hauchecorne, A., Keckhut, P., Bencherif, H., Heinselman, C., Steinbrecht, W., Mlynczak, M., and Russell III, J.: Seasonal oscillations of middle atmosphere temperature observed by Rayleigh lidars and their comparisons with TIMED/SABER observations, J. Geophys. Res., 114, D20103, https://doi.org/10.1029/2008JD011654, 2009.

Dowdy, A., Vincent, R., Igarashi, K., Murayama, Y., and Murphy, D.: A comparison of mean winds and gravity wave activity in the northern and southern polar MLT, Geophys. Res. Lett., 28, 1475-1478, 2001.

Eckermann, S. D. and Vincent, R. A.: First observations of intraseasonal oscillations in the equatorial mesosphere and lower thermosphere, Geophys. Res. Lett., 21, 265-268, https://doi.org/10.1029/93GL02835, 1994.

Garcia, R. R., Dunkerton, T. J., Lieberman, R. S., and Vincent, R. A.: Climatology of the semiannual oscillation of the tropical middle atmosphere, J. Geophys. Res., 102, 26019-26032, https://doi.org/10.1029/97JD00207, 1997.

Hall, C., Aso, T., Tsutsumi, M., Hoffner, J., Sigernes, F., and Holdsworth, D.: Neutral air temperatures at $90 \mathrm{~km}$ and $70^{\circ} \mathrm{N}$ and $78^{\circ} \mathrm{N}$, J. Geophys.Res., 111, D14105, https://doi.org/10.1029/2005JD006794, 2006.

Hall, C., Dyrland, M., Tsutsumi, M., and Mulligan, F.: Temperature trends at $90 \mathrm{~km}$ over Svalbard, Norway $\left(78^{\circ} \mathrm{N} 16^{\circ} \mathrm{E}\right)$, seen in one decade of meteor radar observations, J. Geophys. Res., 117, D08104, https://doi.org/10.1029/2011JD017028, 2012.

Hocking, W., Thayaparan, T., and Jones, J.: Meteor decay times and their use in determining a diagnostic mesospheric temperaturepressure parameter: methodology and one year of data, Geophys. Res. Lett., 24, 2977-2980, https://doi.org/10.1029/97GL03048, 1997.

Hocking, W., Singer, W., Bremer, J., Mitchell, N., Batista, P., Clemesha, B., and Donner, M.: Meteor radar temperatures at multiple sites derived with SKiYMET radars and compared to $\mathrm{OH}$, rocket and lidar measurements, J. Atmos. Sol-Terr. Phy., 66 , 585-593, 2004.

Holdsworth, D., Reid, I., and Cervera, M.: Buckland Park allsky interferometric meteor radar, Radio Sci., 39, RS5009, https://doi.org/10.1029/2003RS003014, 2004.

Holdsworth, D., Morris, R., Murphy, D., Reid, I., Burns, G., and French. W.: Antarctic mesospheric temperature estimation using the Davis mesosphere-stratospheretroposphere radar, J. Geophys. Res., 111, D05108, https://doi.org/10.1029/2005JD006589, 2006.

Holdsworth, D., Murphy, D., Reid, I., and Morris, R.: Antarctic meteor observations using the Davis MST and meteor radars, Adv. Space Res., 42, 143-154, https://doi.org/10.1016/j.asr.2007.02.037, 2008.

Holmen, S. E., Hall, C. M., and Tsutsumi, M.: Neutral atmosphere temperature trends and variability at $90 \mathrm{~km}, 70^{\circ} \mathrm{N}$, $19^{\circ}$ E, 2003-2014, Atmos. Chem. Phys., 16, 7853-7866, https://doi.org/10.5194/acp-16-7853-2016, 2016.

Jia, M., Xue, X., Gu, S., Chen, T., Ning, B., Wu, J., Zeng, X., and Dou, X.: Multiyear observations of gravity wave momentum fluxes in the midlatitude mesosphere and lower thermosphere region by meteor radar, J. Geophys. Res.-Space Phys., 123, 5684 5703, https://doi.org/10.1029/2018JA025285, 2018.

Lee, C., Kim, J., Jee, G., Lee, W., Song, I., and Kim, Y.: New method of estimating temperatures near the mesopause region using meteor radar observations, Geophys. Res. Lett., 43, 10580 10585, https://doi.org/10.1002/2016GL071082, 2016.

Li, T., Leblanc, T., and McDermid, S.: Interannual variations of middle atmospheric temperature as measured by the JPL lidar at Mauna Loa Observatory, Hawaii $\left(19.5^{\circ} \mathrm{N}, \quad 155.6^{\circ} \mathrm{W}\right), \quad$ J. Geophys. Res., 113, D14109, https://doi.org/10.1029/2007JD009764, 2008.

Li, T. Liu, A. Z., Lu, X., Li, Z., Franke, S. J., Swenson, G. R., and Dou, X.: Meteor-radar observed mesospheric semi-annual oscillation (SAO) and quasi-biennial oscillation (QBO) over Maui, Hawaii, J. Geophys. Res., 117, D05130, https://doi.org/10.1029/2011JD016123, 2012.

Li, T., Ban, C., Fang, X., Li, J., Wu, Z., Feng, W., Plane, J. M. C., Xiong, J., Marsh, D. R., Mills, M. J., and Dou, X.: Climatology of mesopause region nocturnal temperature, zonal wind and sodium density observed by sodium lidar over Hefei, China $\left(32^{\circ} \mathrm{N}, 117^{\circ} \mathrm{E}\right)$, Atmos. Chem. Phys., 18, 11683-11695, https://doi.org/10.5194/acp-18-11683-2018, 2018. 
Lima, L., Araújo, L., Alves, E., Batista, P., and Clemesha, B.: Variations in meteor heights at $22.7^{\circ} \mathrm{S}$ during solar cycle 23, J. Atmos. Sol.-Terr. Phy., 133, 139-144, 2015.

Lima, L., Batista, P., and Paulino, A.: Meteor radar temperatures over the Brazilian low-latitude sectors, J. Geophys. Res.-Space Phys., 123, 7755-7766, https://doi.org/10.1029/2018JA025620, 2018.

Liu, L., Liu, H., Chen, Y., Le, H., Sun, Y., Ning, B., Hu, L., and Wan, W.: Variations of the meteor echo heights at Beijing and Mohe, China, J. Geophys. Res.-Space Phys., 121, 2249-2259, https://doi.org/10.1002/2016JA023448, 2016.

Liu, L., Liu. H., Le, H., Chen, Y., Sun, Y., Ning, B., Hu, L., Wan, W., Li, N., and Xiong, J.: Mesospheric temperatures estimated from the meteor radar observations at Mohe, China, J. Geophys. Res.-Space Phys., 1117-1127, https://doi.org/10.1002/2016JA023776, 2017.

Lomb, N.: Least-squares frequency analysis of unequally spaced data, Astrophys. Space Sci., 39, 447-462, 1976.

Ma, Z., Gong, Y., Zhang, S., Zhou, Q., Huang, C., Huang, K., Dong, W., Li, G., and Ning, B.: Study of mean wind variations and gravity wave forcing via a meteor radar chain and comparison with HWM-07 results, J. Geophys. Res.-Atmos., 123, 94889501, https://doi.org/10.1029/2018JD028799, 2018.

Marsh, D., Mills, M., Kinnison, D., Lamarque, J., Calvo, N., and Polvani, L.: Climate Change from 1850 to 2005 Simulated in CESM1(WACCM), J. Climate, 26, 7372-7391, https://doi.org/10.1175/JCLI-D-12-00558.1, 2013.

Picone, J., Hedin, A., Drob, D., and Aikin, A.: NRLMSISE00 empirical model of the atmosphere: Statistical comparisons and scientific issues, J. Geophys. Res., 107, 1468, https://doi.org/10.1029/2002JA009430, 2002.

Placke, M., Hoffmann, P., Becker, E., Jacobi, C., Singer, W., and Rapp, M.: Gravity wave momentum fluxes in the MLT - Part II: Meteor radar investigations at high and midlatitudes in comparison with modeling studies, J. Atmos. Sol.-Terr. Phy., 73, 911920, https://doi.org/10.1016/j.jastp.2010.05.007, 2011.

Reid, I., Holdsworth, D., Morris, R., Murphy, D., and Vincent, R.: Meteor observations using the Davis mesospherestratosphere-troposphere radar, J. Geophys. Res., 111, A05305, https://doi.org/10.1029/2005JA011443, 2006.

Reid, I. M., Spargo, A. J., Woithe, J. M., Klekociuk, A. R., Younger, J. P., and Sivjee, G. G.: Seasonal MLT-region nightglow intensities, temperatures, and emission heights at a Southern Hemisphere midlatitude site, Ann. Geophys., 35, 567-582, https://doi.org/10.5194/angeo-35-567-2017, 2017.

Remsberg, E., Bhatt, P., and Deaver, L.: Seasonal and longer-term variations in middle atmosphere temperature from HALOE on UARS, J. Geophys. Res., 107, 4411, https://doi.org/10.1029/2001JD001366, 2002.

Scargle, J.: Studies in astronomical time series analysis. II. Statistical aspects of spectral analysis of unevenly spaced data, Astrophys. J., 263, 835-853, 1982.
Schwartz, M., Lambert, A., Manney, G., Read, W., and Livesey, N.: Validation of the Aura Microwave Limb Sounder temperature and geopotential height measurements, J. Geophys. Res., 113, D15S11, https://doi.org/10.1029/2007JD008783, 2008.

Stober, G., Jacobi, C., Frohlich, K., and Oberheide, J.: Meteor radar temperatures over Collm $\left(51.31^{\circ} \mathrm{N}, 131^{\circ} \mathrm{E}\right)$, Adv. Space Res., 42, 1253-1258, 2008.

Stober, G., Jacobi, C., Matthias, V., Hoffmann, P., and Gerding, M.: Neutral air density variations during strong planetary wave activity in the mesopause region derived from meteor radar observations, J. Atmos. Sol.-Terr. Phy., 74, 55-63, 2012.

Stober, G., Matthias, V., Brown, P., and Chau, J.: Neutral density variation from specular meteor echo observations spanning one solar cycle, Geophys. Res. Lett., 41, 6919-6925, https://doi.org/10.1002/2014GL061273, 2014.

Takahashi, H., Nakamura, T., Tsuda, T., Buriti, R., and Gobbi, D.: First measurement of atmospheric density and pressure by meteor diffusion coefficient and airglow $\mathrm{OH}$ temperature in the mesopause region, Geophys. Res. Lett., 29, 1165, https://doi.org/10.1029/2001GL014101, 2002.

Xu, J., Smith, A., Yuan, W., Liu, H., Wu, Q., Mlynczak, M., and Russell III, J.: Global structure and long-term variations of zonal mean temperature observed by TIMED/SABER, J. Geophys. Res., 112, D24106, https://doi.org/10.1029/2007JD008546, 2007.

Yi, W., Xue, X., Chen, J., Dou, X., Chen, T., and Li, N.: Estimation of mesopause temperatures at low latitudes using the Kunming meteor radar, Radio Sci., 51, 130-141, https://doi.org/10.1002/2015RS005722, 2016.

Yi, W., Reid, I., Xue, X., Younger, J., Murphy, D., Chen, T., and Dou, X.:, Response of neutral mesospheric density to geomagnetic forcing, Geophys. Res. Lett., 44, 8647-8655, https://doi.org/10.1002/2017GL074813, 2017.

Yi, W., Reid, I., Xue, X., Murphy, D., Hall, C., Tsutsumi, M., Ning, B., Li, G., Younger, J., Chen, T., and Dou, X.: High- and middle-latitude neutral mesospheric density response to geomagnetic storms, Geophys. Res. Lett., 45, 436-444, https://doi.org/10.1002/2017GL076282, 2018a.

Yi, W., Xue, X., Reid, I., Younger, J., Chen, J., Chen, T., and Li, N.: Estimation of mesospheric densities at low latitudes using the Kunmingmeteor radar together with SABER temperatures, J. Geophys. Res.-Space Phys., 123, 3183-3195, https://doi.org/10.1002/2017JA025059, 2018b.

Younger, J., Lee, C., Reid, I., Vincent, R., Kim, Y., and Murphy, D.: The effects of deionization processes on meteor radar diffusion coefficients below 90 km, J. Geophys. Res., 119, 10027-10043, https://doi.org/10.1002/2014JD021787, 2014.

Younger, J., Reid, I., Vincent, R., and Murphy, D.: A method for estimating the height of a mesospheric density level using meteor radar, Geophys. Res. Lett., 42, 6106-6111, https://doi.org/10.1002/2015GL065066, 2015. 